\title{
Upper Ocean Carbon Export and the Biological Pump
}

\author{
Hugh W. Ducklow, Deborah K. Steinberg \\ College of William \& Mary. Gloucester Point, Virginia USA
}

\author{
Ken O. Buesseler \\ Woods Hole Oceanographic Institution. Woods Hole, Massachusetts USA
}

\section{Introduction}

Biology, physics and gravity interact to pump organic carbon into the deep sea. The processes of fixation of inorganic carbon in organic matter during photosynthesis, its transformation by foodweb processes (trophodynamics), physical mixing, transport and gravitational settling are referred to collectively as the "biological pump" (Figure 1). When the Global Ocean Flux Study (GOFS) began in 1984 in the U.S., followed in 1987 by the international Joint Global Ocean Flux Study (JGOFS), several ideas about the functioning of the biological pump formed the conceptual core of the fledgling program:

- The biological and physical processes in the ocean that control the air-sea carbon dioxide $\left(\mathrm{CO}_{2}\right)$ balance are key factors in the planetary climate system.

- The efficiency of the biological pump, expressed as the amount of carbon exported from the surface layer divided by the total amount produced through photosynthesis, is determined by foodweb processes.

- Pump efficiency and export processes can be monitored and understood through a global network of sediment traps and satellite sensors, informed by process studies and models.

In this article, we review the antecedents of JGOFS thought on the relationship between biological processes and carbon export and highlight some JGOFS achievements. We then look ahead to suggest where the field is headed and what the major problems are now, after more than a decade of multidisciplinary research in JGOFS.

\section{Historical And Theoretical Background}

In 1979, Richard Eppley, a biological oceanographer, and Bruce Peterson, a limnologist, published in Nature a synthesis of estimates of primary production and new production rates from several locations in the coastal and open Pacific Ocean. They also demonstrated that the flux of particles out of the surface layer, as measured by sediment traps, generally approximated the large-scale rate of new production. In 1967, Richard Dugdale and John Goering had defined new production as the fraction of the overall net primary production that was supported by external, or "new" inputs of nutrients. They focused on nitrate in deep ocean water supplied to the euphotic zone by vertical mixing and upwelling as the principal new nutrient, but they did explicitly identify $\mathrm{N}_{2}$ fixation as a potential source of new nitrogen (see Michaels et al., this issue). They also highlighted sinking particles as the major pathway for export in the oceanic nitrogen budget. But it was Eppley and Peterson (1979) who articulated the paradigm that came to govern ocean flux studies over the coming decades:

We estimate the sinking flux of POC [Particulate Organic Carbon] in the deep ocean by assuming that new production, as defined by Dugdale and Goering, is quantitatively equivalent to the organic matter that can be exported from the total production in the euphotic zone without the production system running down (Eppley and Peterson, 1979, p. 679).

Eppley and Peterson also defined the ratio of new to total production as the $\mathrm{f}$-ratio and showed that $\mathrm{f}$ was an asymptotic function of the magnitude of total production. This relationship provided an explicit link between remotely-sensed primary production rates and the ocean carbon cycle. If total production could be estimated from remotely-sensed properties, one could apply the Eppley-Peterson algorithm and calculate the export rates as functions of time and space. The f-ratio thus provided both a means to define the efficiency of the biological pump quantitatively and a step toward quantifying the functioning of the pump on a global scale. 


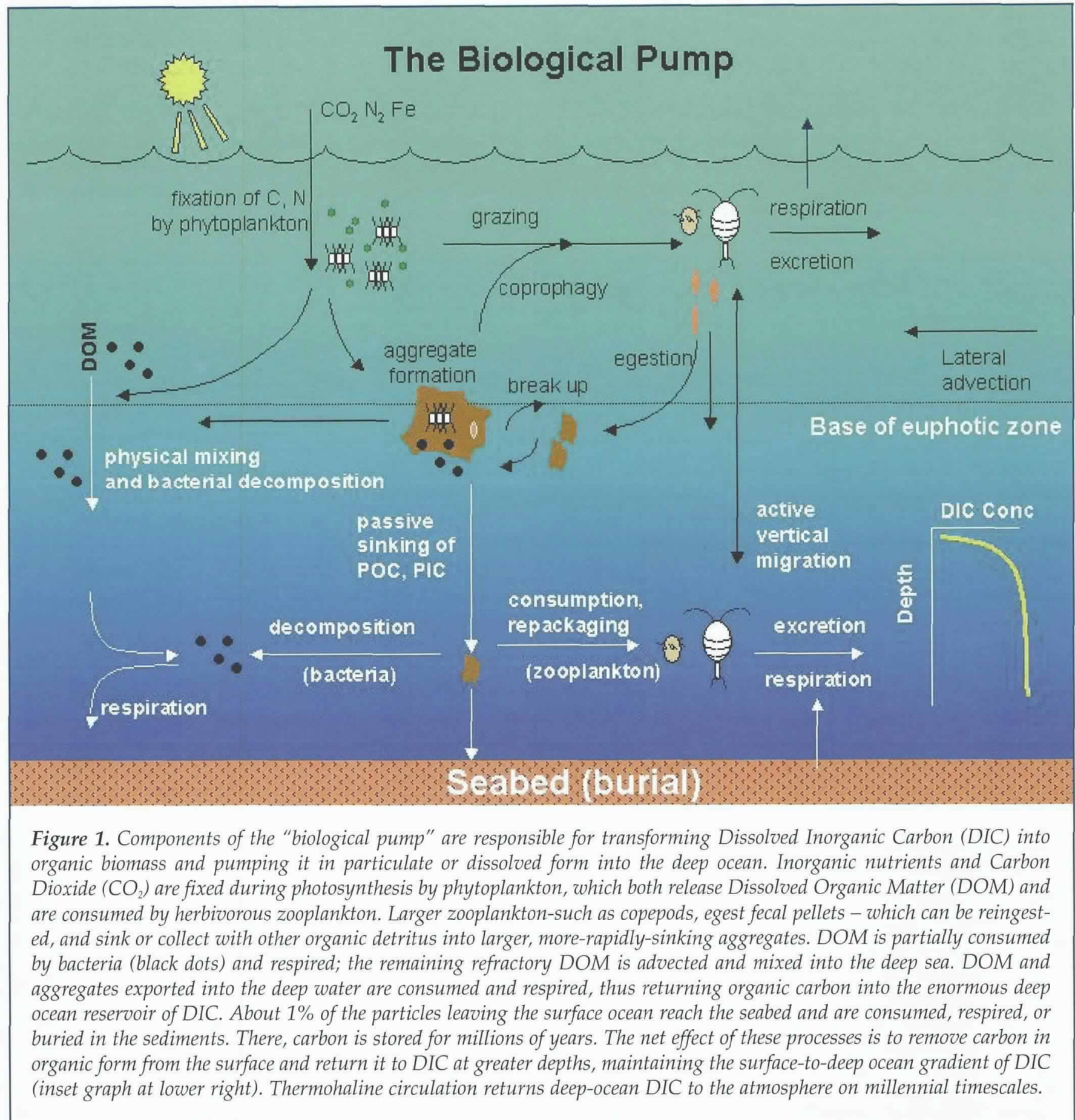

At the kick-off GOFS workshop sponsored by the U.S. National Academy of Sciences, Bruce Frost (1984) gave a seminal talk showing how foodweb structure and processes could influence the amount and fraction of production exported - in other words, how foodweb structure governed the f-ratio. Using a simple, steadystate model (Figure 2) and making simple assumptions about the partitioning of primary production between dissolved and particulate matter and among various size classes of grazers, Frost showed how the f-ratio and e-ratio (ratio of sinking flux to primary produc- tion) varied as functions of the pathways by which nitrogen flowed among different organisms-phytoplankton, large and small grazers and bacteria.

Frost's "simple" model was unique at the time because it included dissolved organic matter flows (see Hansell and Carlson, this issue) and bacteria. It also pointed out the importance of the recycling of detrital materials in the efficiency of the pump. Finally, his model showed how the sometimes vague term "foodweb structure" could be described quantitatively in a system of linear equations. Another important lesson 
learned from this type of model was that the magnitude of export in quasi steady-state systems is set by the level of new production and by physics, rather than by the foodweb per se (Figure 2).

These two early contributions provided important core concepts that JGOFS has depended upon right up to the present: a quantitative relationship between new and total production and the linkages among foodweb structure, biological pump efficiency and export. equivalent, export production. One common method mentioned was bottle incubation experiments using compounds labeled with the ${ }^{15} \mathrm{~N}$ isotope as a tracer for estimating new production, introduced by Dugdale and Goering (1967). Another was the use of upperocean sediment traps to measure particle flux or export production, widely applied by John Martin and his colleagues in the Vertical Transport and Exchange (VERTEX) program of the 1980s. An alternative approach

\section{Limiting Nutrients And Large Cells}

An interesting example of the role of foodweb structure is provided by the case of the diatoms. A second look at Frost's diagram shows that this model emphasizes the microbial "background state" of planktonic systems, the near steady-state assemblage of small-celled plankton kept in check by small, rapidly growing micrograzers. But phytoplankton blooms are often dominated by larger-celled organisms whose growth is stimulated by inputs of new nutrients. In addition to the familiar blooms each spring in the temperate zone and those caused by coastal upwelling, blooms are also triggered by aeolian inputs of iron, as shown in recent dramatic iron-fertilization experiments (Coale et al., 1996). Most plankton variability appears to be driven by diatom blooms, which are limited by inputs of silicon rather than nitrogen. Diatoms are important for several reasons. With mineralized, siliceous shells, they sink like rocks. Because they are large, they support the growth of larger zooplankton. For example, the massive diatom blooms in the ice edge surrounding Antarctica contribute to pulsed export events in that region (Figure 3 ).

\section{Measuring the Strength of the Biological Pump}

At the beginning of JGOFS, Eppley (1989) summarized four general approaches to measuring new production and its

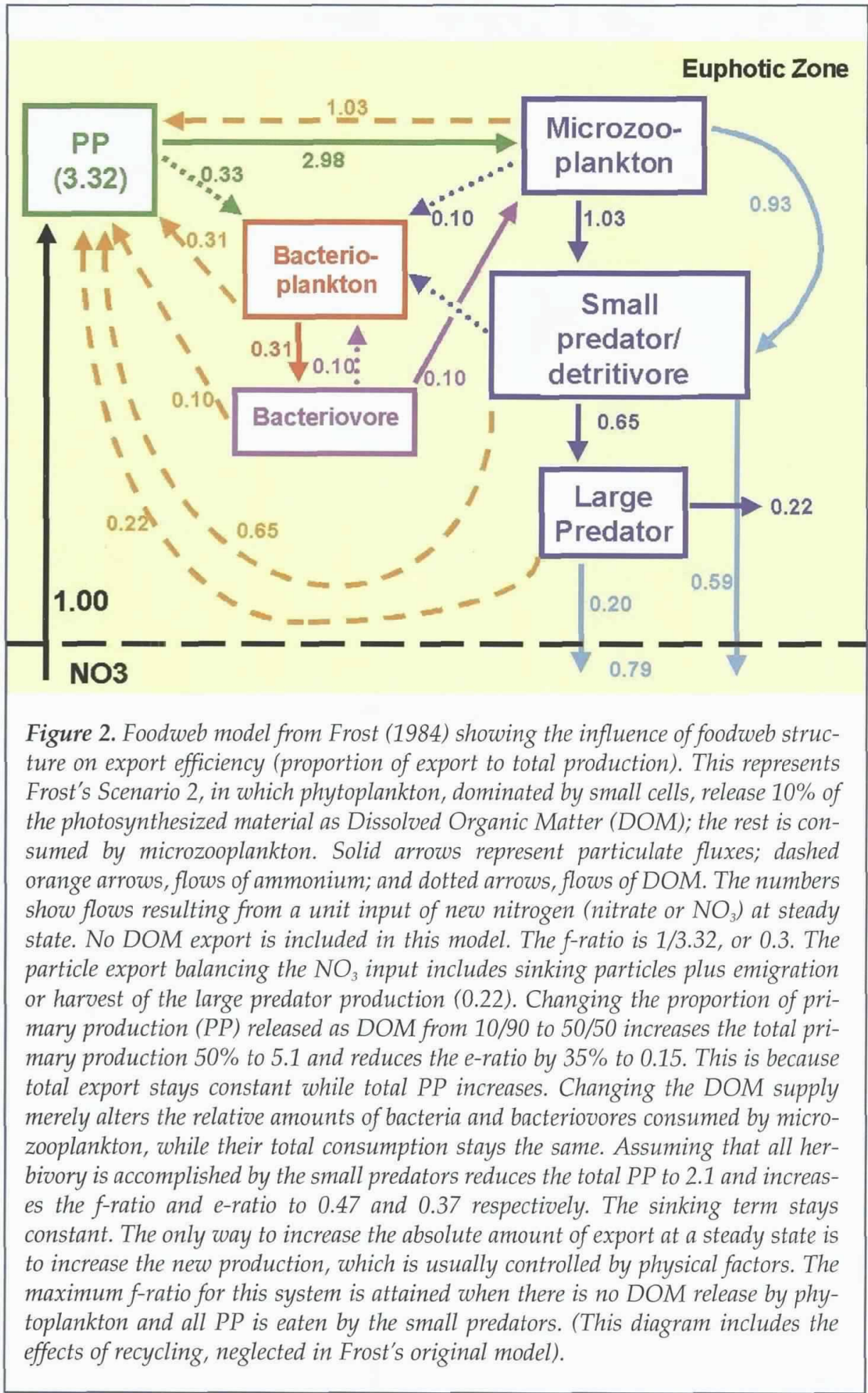


was to use seasonal changes in oxygen or nutrient stocks to examine regional trends in geochemical balances, from which one could draw inferences about net fluxes into or out of the surface ocean. These geochemical balance methods integrated over all forms of carbon transport, including particle settling, active zooplankton migration and the physical mixing of Particulate and Dissolved Organic Carbon (POC and DOC).

The fourth method for measuring the strength of the biological pump involved the use of a naturally occurring particle-reactive radionuclide, thorium-234, as a tracer for sinking particles. Thorium-234 $\left({ }^{234} \mathrm{Th}\right)$ has a half-life of 24 days and is produced at a constant rate from its soluble parent uranium-238 $\left({ }^{238} \mathrm{U}\right)$. Lower ${ }^{234} \mathrm{Th}$ activity in surface waters was found to be associated with higher rates of ${ }^{244} \mathrm{Th}$ loss via sinking particles. As summarized by Eppley, POC export could be calculated by multiplying the particulate ${ }^{234} \mathrm{Th}$ residence time by the stocks of POC, assuming equal particle residence times, an assumption that was not supported by further field studies.

The first JGOFS pilot study in the North Atlantic in 1989 included a new ${ }^{234} \mathrm{Th}$ approach (Buesseler et al., 1992). With this new method, the calculation of the ${ }^{234} \mathrm{Th}$ flux was based on the measured total disequilibrium between ${ }^{234} \mathrm{Th}$ and ${ }^{238} \mathrm{U}$, as in prior studies. The resulting flux was then multiplied by the empirically measured ratio of POC to ${ }^{234} \mathrm{Th}$ or Particulate Organic Nitrogen (PON) to ${ }^{234} \mathrm{Th}$ on particles to determine flux in carbon or nitrogen units.

In theory, the ${ }^{234}$ Th methods should yield particulate flux values equivalent to those derived from trap measurements if they are integrated over the same space and time scales, as both should be when quantifying gravitational settling rates. The apparent discrepancy between ${ }^{234} \mathrm{Th}$ values derived from water-column measurements and the ${ }^{234} \mathrm{Th}$ levels measured in trap fluxes stimulated controversy early in the JGOFS decade. Investigators are still debating the extent of biases in shallow-trap measurements, and it is not certain whether a calibration derived from ${ }^{234} \mathrm{Th}$ measurements can be applied to all particle classes. We still do not know under what conditions and particle regimes traps are accurate, and whether sediment trap biases are primarily the result of the flow of water over, in and out of the trap mouth; sample preservation problems; or the collection of "swimmers", zooplankton that swim into the traps and die.

JGOFS provided a forum for discussion of these issues in two publications, one U.S. and one international (Knauer and Asper, 1989; Gardner, 2000). The ${ }^{234} \mathrm{Th}$ method is limited primarily by its use of empirical ratios of POC to ${ }^{234} \mathrm{Th}$ in samples collected on filters that may or may not reflect the majority of particles responsible for gravitational settling losses. The strongest evidence in support of the new ${ }^{234} \mathrm{Th}$ method is the consistency between ${ }^{234} \mathrm{Th}$-derived export numbers and other estimates of new and export production (Buesseler, 1998). With improvements over the years, this approach has been used in every U.S. JGOFS timeseries and process study.

When comparing methods for ascertaining new and export production, it is important to keep issues of time and space scales in mind. For example, incubations last for 24 hours, but traps are deployed for a number of days or weeks. One must also bear in mind the differences in the processes that each method actually measures, whether gravitational settling, nutrient uptake or DOC transport. A review of new production methods suggested that differences of less than a factor of two are difficult to resolve in general (Ducklow, 


\section{POC flux vs. primary production}

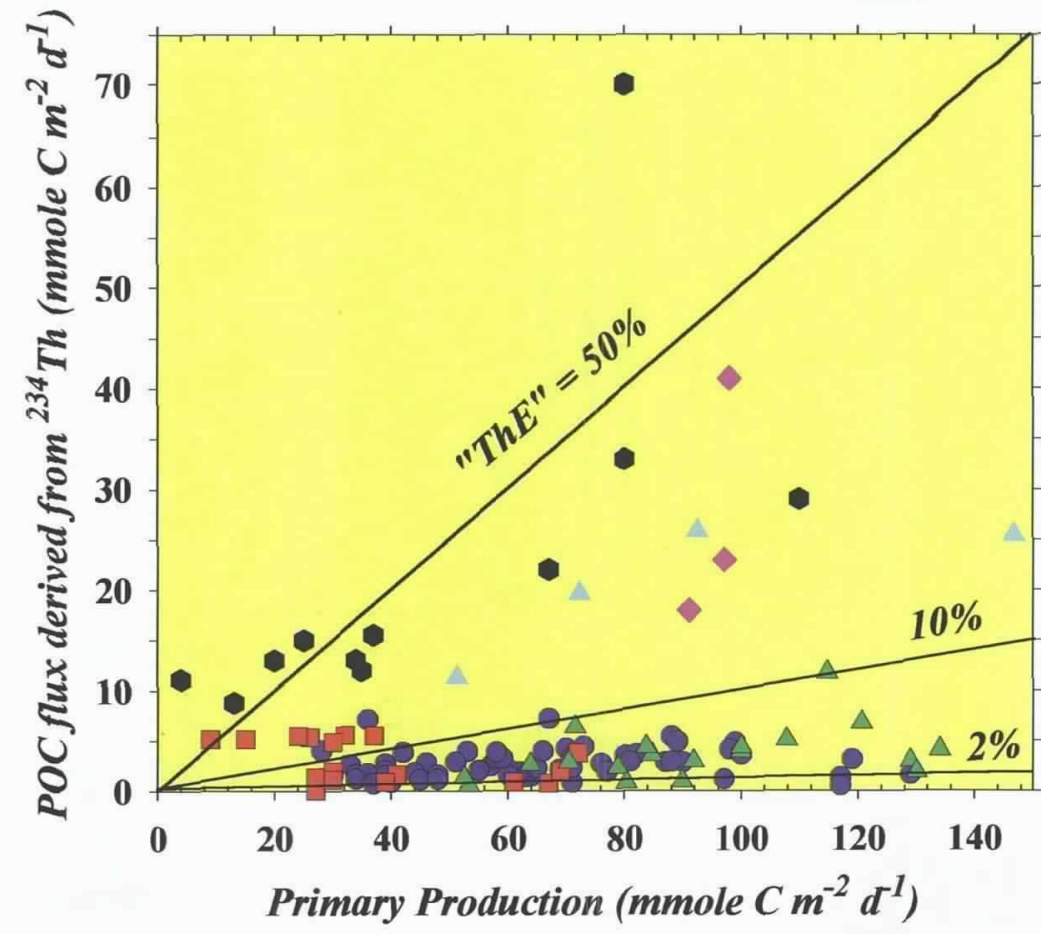

NABE

- EqPac: all data

- BATS: March - October

$\Delta \quad$ Arabian Sea: Jan. - July

A Arabian Sea: Aug./Sept.

- High Latitudes

Figure 4. Summary plot of primary production (determined by standard ${ }^{14} \mathrm{C}$ methods) vs. Particulate Organic Carbon (POC) flux from the upper ocean (100 or $150 \mathrm{~m}$ fluxes determined using ${ }^{234} \mathrm{Th}$ methods). Ratios of POC flux to primary production ("ThE" ratio) for $50 \%, 10 \%$ and $2 \%$ are shown. (Figure updated from Buesseler, 1998).

1995). Future studies will benefit from improvements in trap design, tracer methods such as ${ }^{234} \mathrm{Th}$ and optical methods that quantify particle abundance and composition. With improved compilations of global ocean data sets, mean annual estimates of new production using seasonal oxygen and nutrient changes can be computed more reliably.

\section{Efficiency of the Biological Pump}

An early goal of JGOFS was to understand both seasonal and regional variability and the controls on the efficiency of the biological pump. Pre-JGOFS studies suggested some universal or at least regional relationships in the ratios of new or export production to primary production. But U.S. JGOFS data from the time-series programs near Bermuda and Hawaii and the process studies provided evidence that the efficiency of the biological pump was not easily parameterized and varied considerably between sites and within seasons at any one site. Data from the time-series sites suggest that primary production and sediment-trap fluxes are poorly or even negatively correlated. At Hawaii, David Karl and his coworkers observed an order of magnitude variability in their $150 \mathrm{~m}$ sediment trap record, plus unexpected decoupling of primary production and export. Their data show a three-year decrease in POC flux that coincides with a steady rise in primary production within the normal range of seasonal variability at the Hawaii Ocean Time-series (HOT) study site. They suggest that transient biological processes such as diatom blooms and a major ecosystem change from nitrogen to phosphorus limitation may be responsible for changes in the export/production ratio (see Karl et al., this issue).

The existing ${ }^{234} \mathrm{Th}$-based flux data suggest that while much of the ocean is characterized by low relative ratios of export to production, the locations and times of high export coincide with locations and times of large phytoplankton blooms-diatoms in particular (Figure 4). One example suggesting that diatom blooms control export comes from the Arabian Sea, where the POC flux remains relatively low, except in late summer during the annual southwest (SW) monsoon (Figure $5 a)$. Measurements throughout the year suggest a positive relationship between export flux and the abundance of diatoms, as measured by levels of the pigment fucoxanthin (Figure 5b). The shift towards higher POC flux during the late SW monsoon corresponds to a change in the relationship between export rates and pigment concentrations. The efficiency of the biological 
pump appears to increase, as evidenced by the higher export rates for a given diatom pigment concentration. Also, in the Arabian Sea, the seasonal data show delays greater than a month between the onset of production at the start of the monsoon and export.

The time lag between the uptake of nutrients and subsequent export is one characteristic of plankton blooms that must be considered in ecosystem models and in balancing local estimates of new and export production. Our Arabian Sea data support the hypothesis that large cells control the efficiency of the biological pump in this context, but they do not provide a universal "calibration" that can be used to extrapolate to other areas and times in which this simple relationship is not seen. Such data alone do not tell us whether the export flux is controlled by zooplankton grazing pressures or by nutrient limitation followed by aggregation and settling. While we know from sediment trap data that particle fluxes decrease rapidly with depth between the euphotic zone and 500-1000 m, we have little knowledge of the processes that control this remineralization pattern (see Berelson, this issue). Microbial decomposition, zooplankton consumption and chemical dissolution are all likely to alter the local efficiency of the biological pump.

\section{The Role of Zooplankton}

Zooplankton play a well-documented role in the biological pump by feeding in surface waters and producing sinking fecal pellets. Vertically migrating zooplankton and nekton also play an important role in transport by consuming organic particles in the surface waters at night and metabolizing the ingested food below the mixed layer during the day. One significant contribution of the JGOFS program is an increase in our understanding of how passive sinking of fecal pellets and active transport via diel vertical migration affect patterns and magnitude of fluxes of carbon and associated elements from the surface to the deep ocean.

\section{JGOFS Arabian Sea Process Study}

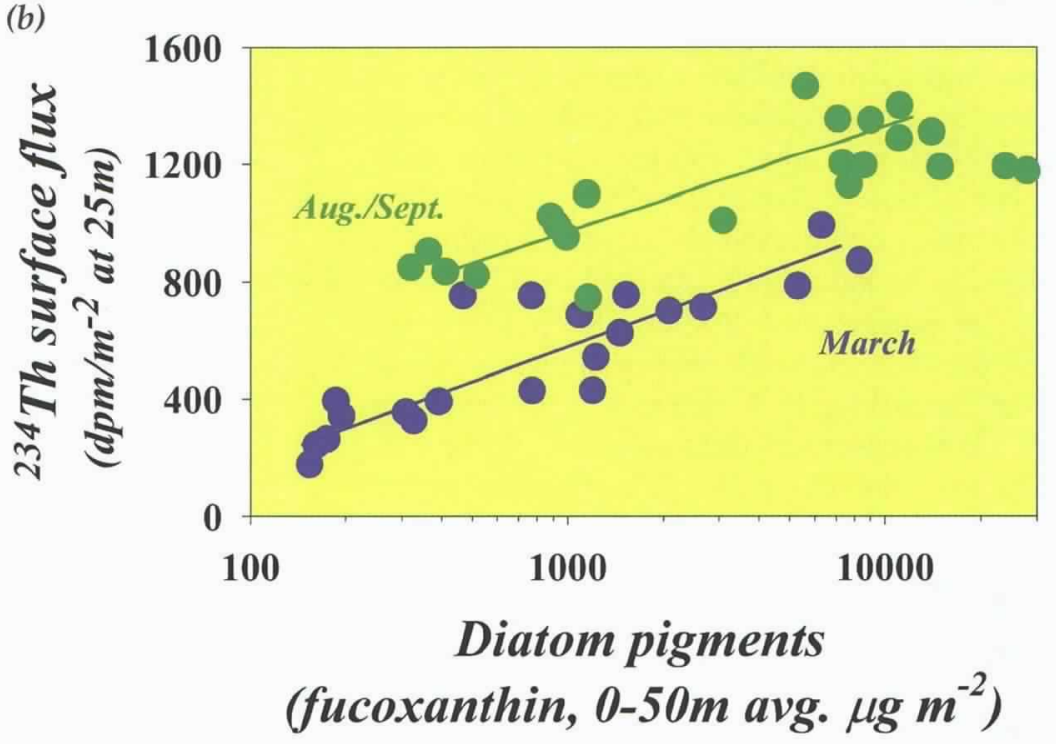

Figure 5. a) Relationship between primary production and Particulate Organic Carbon (POC) export derived from ${ }^{234} \mathrm{Th}$ measurements at $100 \mathrm{~m}$ in the Arabian Sea. Note high ratio of POC flux to primary production in August and September. b) Relationship between ${ }^{234}$ Th export and fucoxanthin (diatom) pigments, showing higher ratio of ${ }^{234}$ Th export to fucoxanthin flux in August and September during the latter part of the southwest monsoon.

\section{Passive Sinking of Fecal Pellets}

While it is clear that much of the carbon in the ocean is recycled through the microbial food web, potentially leaving little energy in the form of food for metazoa, larger organisms are more important than small for export because of the high sinking rates of large cells and the short food chains that produce large sinking particles. Thus the zooplankton play an integral role in the flux of material out of the euphotic zone by consuming the larger phytoplankton and producing sinking fecal pellets.

Changes in zooplankton biomass and composition can dramatically affect the composition and sedimenta- 
tion rate of fecal pellets and thus the export of organic material to the deep ocean. Results from JGOFS show differences in the importance of fecal pellet flux from one ocean basin or season to another. In the Arabian Sea, the grazing of mesozooplankton is significant, and the fecal pellet flux averages $12 \%$ of primary production. This high proportion is linked to high zooplankton biomass, an abundance of large diatoms, and warm temperatures that lead to high zooplankton growth rates (Roman et al., 2000). Estimated fecal flux during the northeast (NE) monsoon and intermonsoon is higher than the measured export flux, indicating some recycling in the surface waters, but makes a smaller contribution during the SW monsoon, when uneaten phytoplankton cells contribute more to the flux.

In the equatorial Pacific, comparisons of data collected in the subtropical oligotrophic gyre and in the mesotrophic High Nutrient-Low Chlorophyll (HNLC) equatorial region show that mesozooplankton biomass is on average 2.5 times higher, and fecal pellet production is roughly 2 times higher in the HNLC region. This contrast indicates a comparatively larger contribution of fecal pellets to the sinking flux in the HNLC equatorial Pacific (Le Borgne and Rodier, 1997). Estimates indicate that mesozooplankton fecal pellets contribute up to $100 \%$ of the sinking POC flux in this region (Dam et al., 1995). Comparisons of data collected at the U.S. JGOFS HOT and the Bermuda Atlantic Time-series (BATS) sites, both located in oligotrophic regions, show on average, a higher annual contribution of fecal pellets to total flux at the HOT site than at the BATS site. This difference is probably associated with the higher mesozooplankton biomass and growth rates at the HOT site (Roman et al., in press).

\section{Zooplankton biomass vs POC flux at BATS}

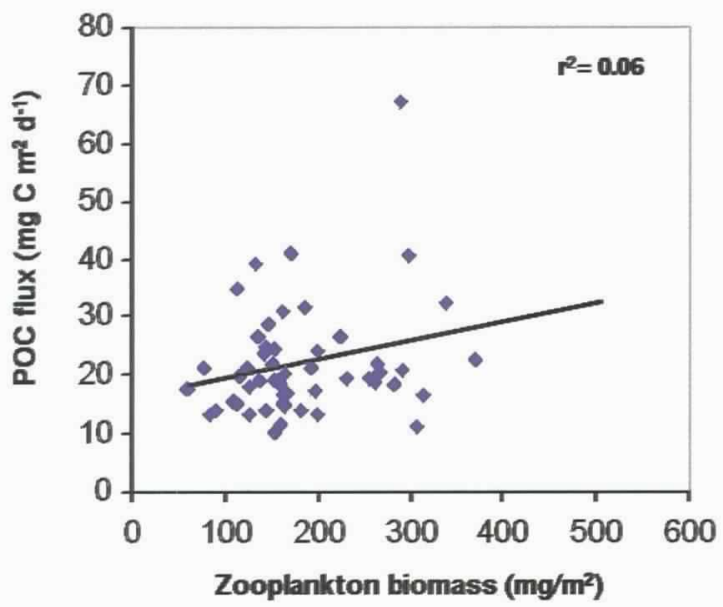

Figure 6. Zooplankton biomass ( $m g \mathrm{C}$ in $0-200 \mathrm{~m}$ ) vs. Particulate Organic Carbon (POC) flux at the U.S. JGOFS Bermuda Atlantic Time-series Study (BATS) site. Data are from April 1994 to December 1998.

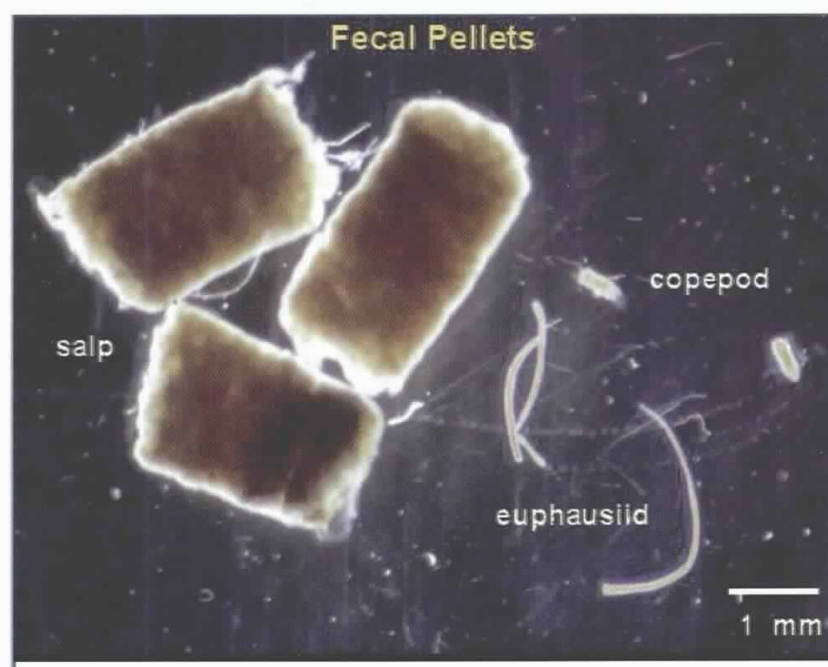

Figure 7. Size comparison of salp fecal pellets with those of other common zooplankton taxa.

Zooplankton biomass alone is not necessarily a good predictor of flux; the species composition of the resident community can have a dramatic effect on the efficiency of the biological pump. For example, there is a positive but weak relationship between monthly zooplankton biomass and organic carbon flux at the BATS site (Figure 6). Analysis of the bloom dynamics of salps (large gelatinous pelagic tunicates) in the 10-year BATS record indicates that salps consume on average $4 \%$ of the primary production, but that fecal pellets from salps can constitute an average of $33 \%$ (with a maximum of $100 \%$ ) of the sediment trap flux at $150 \mathrm{~m}$.

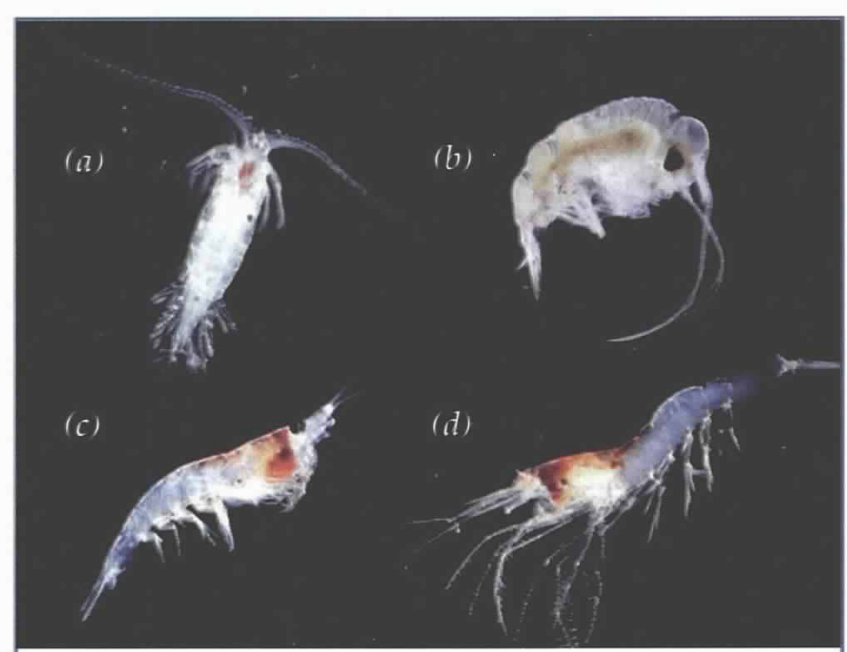

Figure 8. Common vertically migrating zooplankton and micronekton at the U.S. JGOFS Bermuda Atlantic Time-series Study (BATS) site. a) Copepod Pleuromamma xiphias; b) Amphipod Anchylomera blossevillie; c) Euphausiid Thysanopoda aequalis; and $d$ ) Sergestid shrimp Sergestes Atlanticus. 
Although salps are ubiquitous in the global ocean at generally low densities, periodic blooms give rise to dense populations. Due to the high filtration rates of salps and the wide range of suspended particles they are able to consume, salps effectively package small particles into large. As a result, the large and heavier particles or fecal pellets sink rapidly (Figure 7). In the southern ocean, large blooms of Salpa thompsoni exert grazing pressure orders of magnitude higher than the resident copepod populations; this grazing is high enough to prevent the buildup of phytoplankton blooms (Dubischar and Bathmann, 1997). Thus, changes in the relative abundance of zooplankton species, not only increase in biomass alone, may dramatically affect: the amount of primary production consumed; the composition and sedimentation rate of sinking particles; and the flux of organic material to the deep ocean.

\section{Active Export Via Zooplankton Vertical Migration}

Many species of zooplankton that live below the euphotic zone during the day, travel up into the surface waters at night to feed, and then descend again before dawn (Figure 8). Zooplankton can actively increase the magnitude of the export of organic material by transporting surface-ingested material in their guts to deep waters, where this material is then metabolized. Zooplankton molting or mortality from predation also contributes to the transportation of assimilated organic biomass into the deep waters. Initial studies by Alan Longhurst and colleagues (1990) called attention to the potential importance of this process. Since then, JGOFS and other studies have concluded that calculations of export to deep waters should include vertical migration. Including the active transport of carbon and nitrogen through vertical migration increases our estimates of new production by increasing estimates of export.

By viewing Table 1, you will see why vertical migration can increase estimates of export. Table 1 shows the studies of active transport to date, most of which have been carried out through JGOFS. These observations demonstrate that vertically migrating zooplankton can transport a significant amount of carbon to deep water.

While active transport of carbon is on average only $4 \%$ to $34 \%$ of the sinking particulate organic carbon flux measured by sediment traps, it can be as high as $70 \%$ (Table 1). The relative importance of migration versus other fluxes, such as the physical mixing of dissolved organic matter or the passive sedimentation of organic particles, differs with the biomass of 
the migrating organisms, the study location and the season. Although one might expect migrant flux to be more important in oligotrophic regions where a high proportion of zooplankton migrate and particle fluxes are relatively low, this is not always the case. Active flux at the oligotrophic BATS and HOT sites is generally lower or similar to fluxes in more mesotrophic regimes such as the equatorial Pacific. Comparison of the HOT and BATS data sets reveals higher active flux at HOT, in part because of higher migrating biomass at that site and in part because of differences in metabolic rate calculations (Table 1).

We conclude that the relative importance of migration versus other fluxes appears to be more closely tied to the biomass of the migrating community than to the magnitude of gravitational flux. Thus, active flux is likely to be important in systems with a high migrating biomass. While there are a number of studies of inorganic carbon and nitrogen transport by migrators, there are only a handful that have included other kinds of active transport. When forms of transport such as organic excretion, defecation, mortality and molting are considered, estimates of active transport may be more than double the current estimates. These processes are not well known and need attention in future studies.

\section{Conclusions, Models And Prospects}

The simple relationships among production rates, sedimentation and foodweb structure that helped to stimulate the creation of the JGOFS program now look simplistic and naïve. The algorithms relating productivity and export, used in global and cross-system comparisons, break down when one attempts to make predictions within regions and systems. Intensive observations at the U.S. JGOFS time-series and process-study sites revealed the dependency of these relationships on scale and the strong role foodweb structure plays in the magnitude of flux and pump efficiency. The effects of food webs on export fluxes are mediated through conditions that select for the emergence of large organisms-such as diatoms, Trichodesmizm, krill and salps- out of the microbial background. These conditions are still crudely formulated in carbon cycle models. In order to represent the regional and temporal variability of export and its composition accurately, models need new levels of ecological complexity, including parameterization of individual keystone species populations.

New appreciation of the role of foodweb structure and functioning is linked to new radioisotopic approaches and new tools developed during JGOFS, used to sample surface fluxes at finer spatial resolutions and at higher frequencies, than can be achieved with sediment traps alone. The example of export variability illustrates once again that a key JGOFS achievement has been the multidisciplinary cooperation by geochemists, microbiologists and ecologists to attack problems of carbon flux together- across a spectrum of ocean ecosystems.

This is U.S. JGOFS Contribution Number 684.

\section{References}

Buesseler, K.O., 1998: The de-coupling of production and particulate export in the surface ocean. Global Biogeochemical Cycles, 12(2), 297-310.

Buesseler, K.O., M.P. Bacon, J.K. Cochran and H.D. Livingston, 1992: Carbon and nitrogen export during the JGOFS North Atlantic Bloom Experiment estimated from ${ }^{2 * 4} \mathrm{Th}:{ }^{234} \mathrm{U}$ disequilibria. DeepSen Res. I, 39(7-8), 1115-1137.

Coale, K. H., K. S. Johnson, S. E. Fitzwater, R. M. Gordon, S. Tanner, F. P. Chavez, L. Ferioli, C. Sakamoto, P. Rogers, F. Millero, P. Steinberg, P. Nightingale, D. Cooper, W. P. Cochlan, M. R. Landry, J. Constantinou, G. Rollwagen, A. Trasvina and R. Kudela, 1996: A massive phytoplankton bloom induced by an ecosystem-scale iron fertilization experiment in the equatorial Pacific Ocean. Nature, 383, 495-501.

Dam, H.G., X. Zhang, M. Butler and M.R. Roman, 1995: Mesozooplankton grazing and metabolism at the equator in the central Pacific: Implications for carbon and nitrogen fluxes. Deep-Sea Res. II, 42(2-3), 735-756.

Dubischar, C.D. and U.V. Bathmann, 1997: Grazing impact of copepods and salps on phytoplankton in the Atlantic sector of the Southern Ocean. Deep-Sea Res. II, 44(1-2), 415-433.

Ducklow, H.W., 1995: Ocean biogeochemical fluxes: New production and export of organic matter from the upper ocean. Reviews of Geophysics Suppl. (U.S. Natl. report to IUGG, Contributions in Ocean Sciences), 1271-1276.

Dugdale, R.C. and J.J. Goering, 1967: Uptake of new and regenerated forms of nitrogen in primary productivity. Limnol. Oceanogr., 12, 196-206.

Eppley, R.W., 1989: New production: history, methods, problems. In: Productivity of the Ocean: Present and Past. W.H. Berger, V.S. Smetacek and G. Wefer, eds., Wiley \& Sons, New York, 85-97.

Eppley, R.W. and B.J. Peterson, 1979: Particulate organic matter flux and planktonic new production in the deep ocean. Nature, 282, 677-680.

Frost, B.W., 1984: Utilization of phytoplankton production in the surface layer. In: Global Ocean Flux Study: Proceedings of a Workshop, September 10-14, 1984, Woods Hole, Massachusetts. National Academy Press, Washington, D.C., 125-135.

Gardner, W.D., 2000: Sediment trap sampling in surface waters. In: The Changing Ocean Carbon Cycle: A Midterm Synthesis of the Joint Global Ocean Flux Study. R.B. Hanson, H.W. Ducklow, and J.G. Field, eds., Cambridge University Press, Cambridge, 240-284.

Honjo, S., R. François, S. Manganini, J. Dymond and R. Collier, 2000: Particle fluxes to the interior of the Southern Ocean in the Western Pacific sector along $170^{\circ} \mathrm{W}$. Deep-Sea Res. II, 47(15-16), 3521-3548.

Knauer, G. and V. Asper, 1989: Sedinent Trap Technology and Santing: Report of the U.S. GOFS Working Group on Sediment Trap Technology and Sampling. U.S. GOFS Planning Report No. 10, 94 pp.

Le Borgne, R. and M. Rodier, 1997: Net zooplankton and the biological pump: a comparison between the oligotrophic and mesotrophic equatorial Pacific. Deep-Sea Res. II, 44, 2003-2023.

Longhurst, A.R., A.W. Bedo, W.G. Harrison, E.J.H. Head and D.D. Sameoto, 1990: Vertical flux of respiratory carbon by oceanic diel migrant biota. Deep-Sea Res., 37(4), 685-694.

Roman, M., S. Smith, K. Wishner, X. Zhang, and M. Gowing, 2000: Mesozooplankton production and grazing in the Arabian Sea. Deep Sea Res. II, 47, 1423-1450.

Roman, M.R., H.A. Adolf, M.R. Landry, L.P. Madin, D.K. Steinberg and $X$. Zhang., in press: Estimates of oceanic mesozooplankton production: A comparison between the Bermuda and Hawaii time-series data. Deep-Sea Res. II.

Steinberg, D.K., C.A. Carlson, N.R. Bates, R.J. Johnson, A.F. Michaels and A.H. Knap, 2001: Overview of the U.S. JGOFS Bermuda Atlantic Time-series Study (BATS): a decade-scale look at ocean biology and biogeochemistry. Deep-Sea Res. II, 48, 1405-1447. 